\title{
Inhaled Interventions in Cystic Fibrosis: Mucoactive and Antibiotic Therapies
}

\author{
Katharine Hurt ${ }^{\mathrm{a}}$ Diana Bilton ${ }^{\mathrm{b}, \mathrm{c}}$ \\ ${ }^{a}$ Brighton and Sussex University Hospitals, Brighton, and ${ }^{\mathrm{b}}$ Royal Brompton Hospital, and ${ }^{\mathrm{C}}$ Imperial College London, \\ London, UK
}

\section{Key Words}

Cystic fibrosis · Inhaled antibiotics · Hyperosmolar therapy · Mucolytic therapy

\begin{abstract}
Treatment of cystic fibrosis lung disease has developed from an understanding of the abnormal airway surface liquid resulting from a lack of function of the cystic fibrosis transmembrane regulator protein. Mucus plugging resulting in infection and inflammation leads to airway wall destruction and bronchiectasis. Inhaled therapies have formed the backbone of treatments. In combination with antibiotics delivered direct to the airway, mucoactive drugs, including mucolytics and hyperosmolar agents, are utilised to improve mucociliary clearance to reduce infection and inflammation. Until recently, airway therapies were delivered as nebulisers, but we have now entered the era of dry powder inhalers for treatment of cystic fibrosis lung disease. The theory and practice of these therapies are discussed in this review.
\end{abstract}

(c) 2014 S. Karger AG, Basel

\section{Introduction}

Cystic fibrosis (CF) is the most common life-limiting inherited disease in the Caucasian population. Since the discovery of the CF-causing gene in 1989 [1], it has been established that the protein encoded by the gene and called the CF transmembrane regulator (CFTR) functions as a chloride channel on secretory epithelia throughout the body.

In the airways, dysfunction of CFTR leads to a low volume of airway surface liquid. The mouse model that overexpresses the epithelial sodium channel mimics CF lung

Previous articles in this series: 1 . Usmani OS: New developments in inhaled drugs: within and beyond the lungs. Respiration 2014;88:12. 2. Lavorini F, Fontana GA, Usmani OS: New inhaler devices the good, the bad and the ugly. Respiration 2014;88:3-15. 3. Rubin BK, Williams RW: Aerosolized antibiotics for non-cystic fibrosis bronchiectasis. Respiration 2014;88:177-184. 4. Mortensen NP, Hickey AJ: Targeting inhaled therapy beyond the lungs. Respiration 2014;88:353-364.

\section{KARGER}

E-Mail karger@karger.com www.karger.com/res
C 2014 S. Karger AG, Basel

0025-7931/14/0886-0441\$39.50/0
Dr. Katharine Hurt

Department of Respiratory Medicine Royal Sussex County Hospital

Brighton BN2 5BE (UK)

E-Mail Katharine.Hurt@bsuh.nhs.uk 
Fig. 1. Pathophysiology of CF lung disease and opportunities for intervention with inhaled therapies.

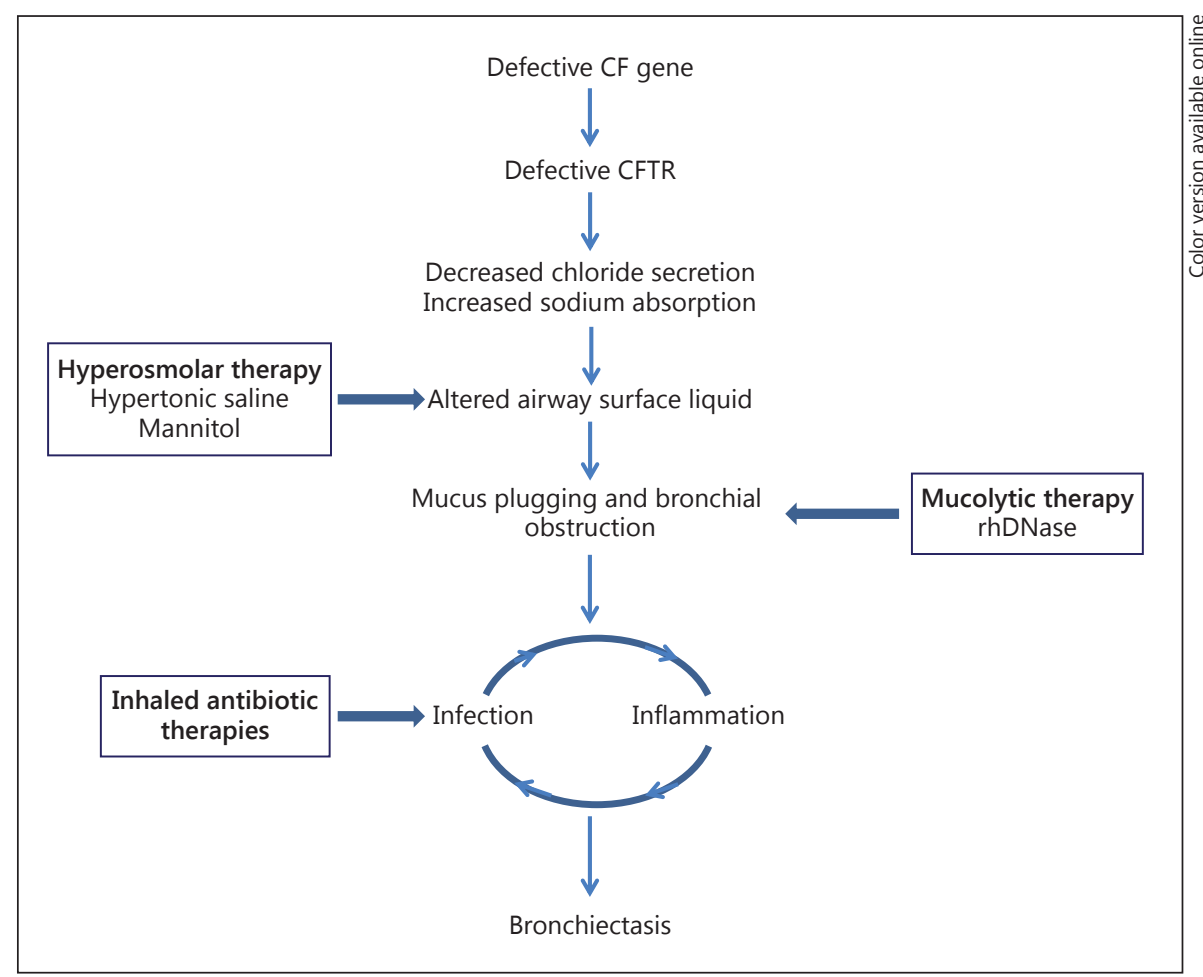

Table 1. Modes of delivery for inhaled therapy in CF lung disease

\begin{tabular}{lll}
\hline & Nebulised & $\begin{array}{l}\text { Dry powder } \\
\text { inhalation }\end{array}$ \\
\hline $\begin{array}{l}\text { Mucolytic drugs } \\
\text { rhDNase }\end{array}$ & + & - \\
Hypertonic saline & + & - \\
Mannitol & - & + \\
Antibiotic therapy & & + \\
$\quad$ Colistin & + & + \\
Tobramycin & + & + \\
Aztreonam & + & - \\
\hline
\end{tabular}

disease, producing mucus plugging and intense neutrophilic inflammation associated with infection as a result of airway obstruction [2]. More recently, the development of the CF pig has confirmed that the CFTR defect results in abnormal mucociliary clearance [3].

Environmental bacteria then infect the $\mathrm{CF}$ airway causing the so-called vicious cycle of infection and inflammation, leading to airway wall damage and bronchiectasis. It is recognised that bronchiectasis occurs early on in a person with CF [4] and progresses over time with associated decline in lung function, ultimately resulting in respiratory failure. Over $95 \%$ of morbidity and mortality arises from respiratory disease. Figure 1 demonstrates the well-described vicious cycle that develops within the $\mathrm{CF}$ airway and the points at which inhaled therapies provide specific interventions to alter the progression of disease.

This article aims to review the developments in inhaled therapies in CF, which for the purposes of this review fall neatly into two categories. First are the mucoactive therapies that address the altered airway milieu occurring in CF (whether at the basic defect level or as a result of infection and inflammation), and second are the antibiotic therapies dealing with the airway infections. Table 1 highlights the different available modes of delivery for the key medicines.

\section{Mucoactive Inhaled Therapy}

Mucoactive drugs fall into two categories, either mucolytic or hyperosmolar. Recombinant human deoxyribonuclease (rhDNase, dornase alfa, Pulmozyme; Roche, Welwyn Garden City, UK) remains the only licensed mucolytic with proven efficacy in CF. 
Inhalation of dornase alfa reduces the viscoelasticity of sputum by breaking down DNA released by neutrophils which flood into infected airways in a fruitless attempt to phagocytosis infecting bacteria [5]. The benefits of nebulised rhDNase have been well documented. The initial 6-month placebo-controlled study demonstrated significant improvement in pulmonary function $\left(\mathrm{FEV}_{1}\right)$, with an associated reduction in pulmonary exacerbations requiring intravenous therapy [6]. This confirmed the hypothesis that enhancing clearance of secretions full of bacteria, neutrophils and their deleterious products would reduce inflammation and, hence, exacerbations. Indeed, a subsequent bronchoscopic study showed a reduction in free elastase after therapy with rhDNase [7]. A Cochrane review has further supported the efficacy of rhDNase [8], and recent evidence suggests that the use of rhDNase has been associated with an increase in survival of those with severe end-stage disease [9].

rhDNase has proven to be safe and effective over the years and is now central to pulmonary guidelines in $\mathrm{CF}$ care. The European Cystic Fibrosis Society has recommended the use of rhDNase in all patients with CF over the age of 6 years, regardless of the severity of lung disease [10] and, similarly, it has become the standard of care in the USA [11]. DNase may be useful in infants, but further evidence is required [12].

The current debate regarding the use of rhDNase relates to the best timing of this therapy and the timing of accompanying airway clearance. It appears that rhDNase requires time to dwell in the lung for at least $30 \mathrm{~min}$ in order for sputum to show changes in viscosity and pourability $[13,14]$. It therefore follows that one would expect the best outcomes to occur if airway clearance techniques are performed at least $30 \mathrm{~min}$ after the inhalation of rhDNase. A study in a young CF population demonstrated no difference when rhDNase was inhaled just before sleep compared to earlier in the day followed by airway clearance. However, for older patients with more severe disease and larger volumes of sputum, it appears logical to recommend ensuring that liquefied sputum is properly cleared before going to sleep.

rhDNase remains an efficacious therapy, but the CF physician must remember the time and effort required by the patients to use this therapy effectively. It is imperative, therefore, that the patients themselves work out when is the most convenient time to perform the inhalation. Many patients choose to do this when coming in from school, college or work so that an airway clearance session can be completed early in the evening before other impor-

Inhaled Interventions in CF: Mucoactive and Antibiotic Therapies tant activities, such as socialising, etc. As yet there have been no developments in producing a dry powder version of rhDNase.

\section{Hyperosmolar Therapy}

Understanding of the low-volume airway surface liquid theory led researchers to postulate that exacerbations would be reduced if the airway fluid could be enhanced using hyperosmolar therapy. Hypertonic saline was already in use in respiratory medicine to induce sputum in order to obtain samples for culture rather than resort to bronchoscopy. It was then only a small leap to construct a trial of nebulised hypertonic saline in CF to determine whether administration via a nebuliser twice daily over 6 months would improve lung function and/or reduce exacerbations. Elkins et al. [15] randomised 164 patients to normal saline or hypertonic $7 \%$ saline twice daily, and demonstrated a relative reduction in exacerbations of $56 \%$, despite failing to meet the primary endpoint of a significant difference in the rate of change in lung function. Less than $40 \%$ of patients in the study were on rhDNase.

It is noteworthy that the use of hypertonic saline was preceded by the use of a protective bronchodilator in order to avoid preventable bronchoconstriction. We believe that hypertonic saline exerts its effects of reducing exacerbations by enhancing mucociliary clearance, but more recent data suggest that hypertonic saline may have direct antibacterial effects and inhibit biofilm growth [16].

The question has been asked as to whether lower concentrations of hypertonic saline can be used with the same good effects. The SALTI CF trial sought to address this and the preliminary results presented suggest that, whilst $3 \%$ concentration has an effect, the maximal effects are with $7 \%$ in terms of lung function and exacerbation, and that only $7 \%$ produced significant changes in quality of life [17].

Guidelines for pulmonary therapies in CF recommend hypertonic saline [10, 11]. Mannitol, a sugar alcohol already used in medicine as an osmotic agent [18], represents an alternative hyperosmolar therapy. When inhaled it draws water into the airway by creating an osmotic gradient and has been shown to increase mucociliary clearance in CF and other obstructive airway diseases $[19,20]$.

Mannitol was originally developed as a bronchial provocation test, which may initially have raised concerns in the CF community regarding bronchoconstric- 
tion in routine use. A program of clinical trials, including a mannitol challenge test for all patients, has led to this medication being licensed in Europe and Australia.

Dry powder mannitol is prepared through a process of spray drying. Mannitol solution undergoes a process of liquid atomisation followed by hot air drying. The fine mist becomes a dry powder with particles that are spherical in shape and of respirable size.

The device is a redesign of the cyclohaler, which has low intrinsic resistance. To use the device, the capsulepiercing buttons need to be pressed and the patient is required to inhale a controlled deep breath from the mouthpiece. A mesh and a centrifugal spinning action maximize the number of particles in the respirable range. Ten capsules of $40 \mathrm{mg}$ each make up the standard dose of $400 \mathrm{mg}$, each requiring a single individual inhalation. This process takes less than 5 min [21].

The dose of $400 \mathrm{mg}$ was chosen from a dose-ranging study in CF patients [22]. A study over 2 weeks showed a benefit in terms of improved lung function [23], and large phase 3 studies were performed to assess the benefit of inhaled dry powder mannitol (Bronchitol ${ }^{\circledR}$ ) on lung function and exacerbations. Patients already on hypertonic saline were excluded from the studies.

In the first UK, Australian and New Zealand study, involving 389 patients, a significant improvement in $\mathrm{FEV}_{1}$ of $92.9 \mathrm{ml}$ was achieved compared to controls ( $\mathrm{p}<0.001)$. Furthermore, there was a $35.4 \%$ reduction in the incidence of an exacerbation on mannitol $(\mathrm{p}=0.045)$ [24]. Fifty-five per cent of the patients were also taking rhDNase, and it was notable that patients benefitted from mannitol regardless of rhDNase use or not. The subsequent global study demonstrated a $105-\mathrm{ml}$ mean improvement in $\mathrm{FEV}_{1}$ in the mannitol group. However, statistical significance was narrowly missed for the primary endpoint of the study (i.e. the difference in absolute $\mathrm{FEV}_{1}$ between the treated and control groups) [25].

The pooled data from both studies indicated efficacy regardless of DNase use in both improving lung function and reducing exacerbations [26]. However, the effect size was greatest in adults rather than children. The EMA granted the licence for adults and is awaiting further studies in the paediatric population.

Importantly, the trials established the safety of inhaled mannitol. The initial challenge test is important to ensure that patients who bronchoconstrict when exposed to lower doses of mannitol are not prescribed this medication chronically. The percentage of subjects who passed the mannitol trial was reported to be $87.8 \%$ [24]. Importantly, there was no evidence that patients passing the man- nitol tolerance test developed subsequent bronchoconstriction later on in chronic use.

Mannitol has the advantage of being administered as a dry powder inhaler which is portable. Thus, patients with CF have several options for inhaled therapy to assist in the clearance of airway secretions in order to reduce exacerbations. It makes sense to utilise both mechanisms, i.e. a reduction in viscosity by cleaving DNA and a choice of one of the hyperosmolar agents to improve the airway surface liquid.

The trials of the hyperosmolar agents included patients on DNase and there appeared to be a benefit, but data on the long-term effects of dual mucolytic plus hyperosmolar therapy are lacking. Registry studies may help us define whether dual therapy should be recommended for all patients.

In the meantime, whilst approaching patients with a rule that clearance of secretions should be optimised, we must take into account the possibility that, if overburdened with therapies, and particularly nebulised therapies, adherence will be poor [27]. Thus, individual trials of therapy can be helpful to establish benefit and tolerability versus treatment burden. A patient already on oncedaily nebulised rhDNase may prefer to add mannitol as a dry powder inhaler twice daily, rather than further twice daily nebulised hypertonic saline. However, choices may change both with the age of the patient and the severity of the disease. Suggestions that use of rhDNase alters survival [28] mean it is likely that, if choosing a single agent, we may favour the mucolytic. However, a teenager willing only to take a single agent may choose the portability and ease of use of the mannitol inhaler.

\section{Chronic Suppressive Inhaled Antibiotic Therapy}

There is a distinct pattern of microorganisms found in the airways in CF. The prevalence of the most common organisms found in the lungs of people with CF in the UK is shown in figure 2. It is recognised that chronic infection with Pseudomonas aeruginosa is a major driver to airway damage and, hence, increased morbidity and mortality in CF. Treating airway infection is the key to preventing airway damage and loss of lung function.

The original paper by Hodson et al. [29] published in Lancet demonstrated that antibiotics traditionally given intravenously could be nebulised by CF patients with beneficial effects on lung function. Since those pioneering days, the whole science of delivering antibiotics to the airway has developed with the production of new formula- 
Fig. 2. UK registry data on the age-related prevalence of airway infections in CF [41]. MRSA = Methicillin-resistant Staphylococcus aureus.

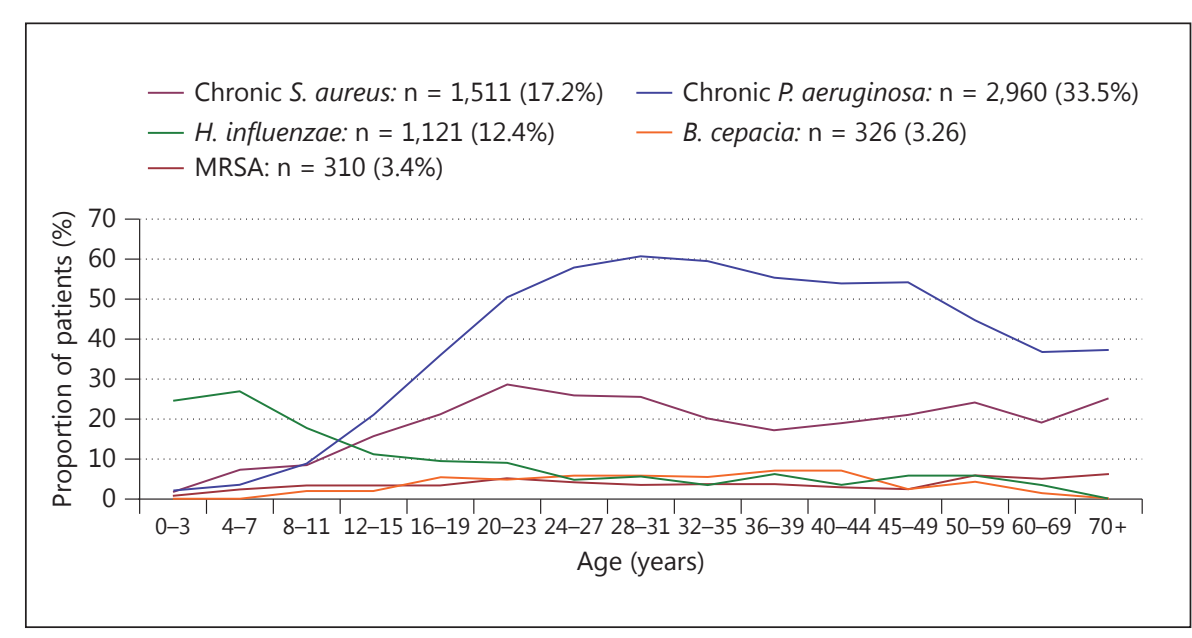

tions specifically made for airway delivery and, most recently, the licencing of dry powder inhaled antibiotics.

The principle of delivering antibiotics to the airways is a simple one of being able to ensure that high concentrations of a chosen effective antibiotic are delivered to the site of infection to facilitate maximum efficacy and allow long-term therapy with minimal systemic absorption, thus limiting the risks of toxicity. The principle of chronic suppressive therapy for PA infection became established in Europe following a study by the Copenhagenbased group of Høiby and colleagues [30]. Their work showed a lack of decline in lung function compared to controls after an intravenous clean-out in patients receiving nebulised Colistin twice daily for 3 months.

Colistin, an effective antipseudomonal therapy, was chosen as it was rarely used for intravenous therapy and development of resistance was thought to be very unlikely. There were, however, significant knowledge gaps in terms of dose-ranging studies to establish the best dose regimen and the best nebuliser device in terms of delivery.

The studies which facilitated the licencing of TOBI ${ }^{\circledR}$ set the gold standard for evaluation of inhaled antibiotic therapy in CF. In contrast to Colistin, where the intravenous preparation was used for inhalation, TOBI was developed as a preservative-free nebulised solution with appropriate animal toxicity studies before being studied in CF patients. The seminal paper by Ramsey et al. [31] reported improved pulmonary function, reduced PA density and a reduction in the need for intravenous antibiotic therapy in the TOBI-treated group compared to the placebo arm. In that study, the antibiotic was delivered twice daily for 28 days followed by a 28 -day off cycle.

Inhaled Interventions in CF: Mucoactive and Antibiotic Therapies
The armamentarium has been further expanded by the development of aztreonam lysine, another antipseudomonal antibiotic specifically modified from the intravenous preparation in order to produce a safe and effective therapy for nebulisation. The studies demonstrated the best efficacy at a thrice- rather than twice-daily dosing regimen [32]. A comparative study of aztreonam lysine versus TOBI confirmed the efficacy of this new drug in maintaining lung function and reducing the requirement for intravenous therapy [33]. Aztreonam, like TOBI, was delivered in 28-day cycles, i.e. a regimen of a month on followed by a month off.

The phase 3 studies of nebulised antibiotics are driven by the licencing requirements of regulatory authorities, but do not allow us to assess the best regimen in clinical practice. Questions remain as to whether aztreonam lysine and TOBI should be used in a month on/month off fashion, form part of an alternating regimen, or simply be used singly on a continuous basis.

The regimen of administration twice daily for a month followed by a month free of antibiotics was purposely designed originally in the TOBI studies. This approach was adopted because of background concerns that long-term twice-daily dosing throughout the year could generate more resistant organisms. In clinical practice, however, the month on/month off regimen has not been adopted worldwide, and the month off does not fit the theory that daily chronic suppression is the way to prevent lung disease progression. The debate regarding whether continuous inhaled antibiotic therapy is better than intermittent month on/month off therapy continues, and is not easily resolved in the absence of a randomised controlled trial [34]. The answers may emerge from registry-based long- 
term observational studies, but in the meantime clinicians make decisions based on individual patient needs. A CF patient who has moderately severe disease may not tolerate the month-off treatment, noticing a decline in lung function in association with increased sputum. Thus, to avoid the decline during the month off, the clinician will choose with the patient to either continue the same agent on a continuous basis or to fill the month off with an alternative antibiotic. The patients may choose the regimen that best fits their lifestyle. Some will prefer continuous TOBI in favour of a regimen which includes aztreonam lysine simply based on a preference for dosing twice rather than thrice a day.

TOBI was licensed in combination with a jet nebuliser. In an effort to reduce treatment time, clinicians moved to employing the newer alternative of mesh technologies, which create a soft mist and are significantly faster to administer. In order to generate an aerosol they either have a vibrating or fixed mesh, with a piezoelectric element with microscopic holes made to measure for different products. The mesh nebulisers are silent and portable as there is no need for a compressor, and can operate on batteries as well as mains. The final finesse of nebuliser devices is what is known as smart computer technology, which senses the user's breathing pattern and sets delivery during a preset fraction of inspiration. Using this combination of mesh and smart technology, the I-neb (Philips Respironics, Parsipanny, N.J., USA) represents one of the most efficient devices with almost no loss of drug during exhalation, meaning that the dose placed in the nebulising chamber can be reduced.

They are also more efficient in ensuring a higher dose is delivered to the lung. Studies to formally assess equivalent efficacy and safety are often lacking. Ideally, only the drug-device combinations tested in clinical studies for efficacy and safety should be used, particularly where systemic absorption could be different because of increased lung deposition to small airways. TOBI, for instance, may have a different systemic absorption when used through a device using the vibrating mesh technology, which could alter the safety profile regarding oto- or renal toxicity. On the other hand, the benefits of better delivery to small airways using new nebuliser technology have been demonstrated for rhDNase [35].

There is no doubt that patients prefer the fast delivery time of less than 5 min of the vibrating mesh technology devices. Aztreonam lysine was licensed with the eFlow ${ }^{\circledR}$ rapid system, which has made thrice-daily dosing more palatable because of the speed of delivery.
The drive to reduce the burden of treatment for CF patients has fuelled the development of dry powder-inhaled antibiotics. It is clear that, above all other therapies, nebulised therapy is the most burdensome to patients [27], and that overall adherence to nebulised antibiotic therapies is low. In one study, in which adherence was monitored electronically, a median adherence at $35 \%$ was shown [36].

Dry powder inhalers for antibiotics involve the dry powder antibiotic being packaged in a capsule. Tobramycin dry powder is produced using Pulmosphere technology (Novartis AG, Basel, Switzerland). This technique involves spray drying the product to produce porous particles that disperse rapidly. To produce a lung dose equivalent to $300 \mathrm{mg}$ of nebulised tobramycin, four 28$\mathrm{mg}$ capsules are inhaled through a low-resistance inhaler. An inspiratory flow rate of 30 litres per minute is sufficient to generate drug release and dispersion of the aerosol particles with a mass median aerodynamic diameter of $<4 \mu \mathrm{m}$ [37]. Clinical trials have demonstrated the efficacy and equivalence to TOBI nebulised therapy [38]. The inhaler is associated with more patient satisfaction than the nebulised therapy.

We do not as yet have evidence that this definitely improves adherence, but it is hoped that a more portable device that is easy to use will help adherence. In addition to being quick and easy to use, a dry powder inhaler obviates the need for nebuliser cleaning, which is often an underestimated burden for patients.

Cough is a frequent side effect $[38,39]$, which may be related to rapid inspiratory flows. In our centre, patients are carefully trained in the use of dry powder inhalers by physiotherapists with the aim of reducing the incidence of cough by avoiding high inspiratory flow rates.

Colobreathe (Forest Laboratories Inc., New York, N.Y., USA) is the dry powder formulation of the antibiotic Colistin. The particles are micronised, meaning they are less easily dispersed than the porous particles in the Pulmosphere technology. For each dose administration, a single capsule of $125 \mathrm{mg}$ is said to be equivalent to the 160-mg dose of nebulised Colistin. There are no published data describing the aerosol characteristics of the Colobreathe DPI. An open-label study demonstrated non-inferiority to nebulised Tobramycin in terms of the effect on lung function [40].

Thus, there are now several options for children and adults with CF for treating chronic PA infection. Choosing the appropriate regimen will take into account the patient's or parental preferences. It is crucial that, whatever antibiotic and inhalational device is chosen, appro- 
priate education and advice is given on its use. In particular, for the dry powder devices, education on inhalation at an inspiratory flow that maximises lung deposition will be important. For the nebulised antibiotics it is crucial for patients to understand the matching of specific drugs to particular devices.

The next year or so will see more new inhalational antibiotics coming for licence in CF. Once-daily nebulised liposomal Amikacin and twice-daily nebulised Levofloxacin have both been evaluated. Choosing the most effective regimen for each patient will require careful assessments of responses not only in terms of lung function and exacerbation frequency, but also of treatment burden. The regimen which does not favour either the development of resistance or emergence of new pathogens would be favoured, but such information will only be available some years down the line. It is important that registry data begins to accumulate such information so that, in time, we will be able to choose the best regimen.

\section{Conclusion}

Both mucoactive and antibiotic therapies are key to maintaining lung function and reducing exacerbations in CF lung disease. The move toward finding ways of cutting down treatment burden is welcomed. The new dry powder inhalers offer hope of a more acceptable regimen for patients trying to maintain quality as well as length of life. Although there are challenges to developing inhaled rather than nebulised therapies, this should clearly remain a goal for the companies involved.

\section{References}

$>1$ Riordan JR, Rommens JM, Kerem B, et al: 10 Heijerman H, Westerman E, Conway S, et al: Identification of the cystic fibrosis gene: cloning and characterization of complementary DNA. Science 1989;245:1066-1073.

-2 Zhou Z, Duerr J, Johannesson B, et al: The $\beta \mathrm{ENaC}$-overexpressing mouse as a model of cystic fibrosis lung disease. J Cyst Fibros 2011; 10:S172-S182.

>3 Hoegger MJ, Fischer AJ, McMenimen JD, et al: Impaired mucus detachment disrupts mucociliary transport in a piglet model of cystic fibrosis. Science 2014;345:818.

4 Sly PD, Gangell CL, Chen L, et al: Risk factors for bronchiectasis in children with cystic fibrosis. N Engl J Med 2013;368:1963-1970.

$>5$ Shak S: Aerosolised recombinant human DNase 1 for the treatment of cystic fibrosis. Chest 1995; 107:65S-70S.

-6 Fuchs HJ, Borowitz DS, Christiansen DH, et al: Effect of aerosolized recombinant human DNase on exacerbations of respiratory symptoms and on pulmonary function in patients with cystic fibrosis. The Pulmozyme Study Group. N Engl J Med 1994;331:637-642.

$>7$ Paul K, Rietschel E, Ballmann M, et al: Effect of treatment with dornase alpha on airway inflammation in patients with cystic fibrosis. Am J Respir Crit Care Med 2004;169:719725 .

$>8$ Jones AP, Wallis C: Dornase alfa for cystic fibrosis. Cochrane Database Syst Rev 2010; 3:CD001127.

$\checkmark 9$ George PM, Banya W, Pareek N, et al: Improved survival at low lung function in cystic fibrosis: cohort study from 1990-2007. BMJ 2011;342:1008.
Inhaled medication and inhalation devices for lung disease in patients with cystic fibrosis: a European consensus. J Cyst Fibros 2009;8: 295-315.

11 Mogayzel PJ, et al: Cystic fibrosis pulmonary guidelines: chronic medications for maintenance of lung health. Am J Respir Crit Care Med 2013;187:680-689.

$>12$ Berge MT, van der Weil E, Tiddens HA, et al: DNase in stable cystic fibrosis infants. J Cyst Fibros 2003;2:183-188.

13 van der Giessen L: Does the timing of inhaled dornase alfa matter? J Cyst Fibros 2009;8:S6S9.

14 Shak S, Capon DJ, Hellmiss R, et al: Recombinant human DNase 1 reduces the viscosity of cystic fibrosis sputum. Proc Natl Acad Sci USA 1990;87:9188-9192.

15 Elkins MR, Robinson M, Rose BR, et al: A controlled trial of long-term inhaled hypertonic saline in patients with cystic fibrosis. $\mathrm{N}$ Engl J Med 2006;354:229-240. Advances toward the elucidation of hypertonic saline effects on Pseudomonas aeruginosa from cystic fibrosis patients. PLoS One 2014;9:e90184.

17 Dwyer T, Elkins M, Dentice R, et al: Saline at lower tonicity in cystic fibrosis (SALTI-CF) trial: a randomised controlled trial comparing $0.9 \%$ vs. $3 \%$ vs. $6 \%$ nebulised saline. J Cyst Fibros 2013;12:S19.

18 Rowe RC, Sheskey PJ, Weller PJ (eds): Handbook of Pharmaceutical Excipients. Chicago, Pharmaceutical Press, 2003.
16 Michon A-L, Jumas-Bilak E, Chiron R, et al:
19 Daviskas E, Anderson SD, Brannan JD, et al: Inhalation of dry powder mannitol increases mucociliary clearance. Eur Respir J 1997;10: 2449-2454.

20 Robinson M, Daviskas E, Ebert S, et al: The effect of inhaled mannitol on bronchial mucus clearance in CF patients: a pilot study. Eur Respir J 1999;14:678-685.

21 Hurt K, Bilton D: Inhaled mannitol for the treatment of cystic fibrosis. Expert Rev Respir Med 2012;6:19-26.

-22 Teper A, Jaques A, Charlton B: Inhaled mannitol in patients with cystic fibrosis: a randomised open label dose response trial. J Cyst Fibros 2011;10:1-8.

23 Jaques AJ, Daviskas E, Turton JA, et al: Inhaled mannitol improves lung function in cystic fibrosis. Chest 2008;133:1388-1396.

24 Bilton D, Robinson P, Cooper P, et al: Inhaled dry powder mannitol in cystic fibrosis: an efficacy and safety study. Eur Respir J 2011;38: 1071-1080.

-25 Aitken ML, Bellon G, De Boeck K, et al: Long term inhaled dry powder mannitol in cystic fibrosis: an international randomised study. Am J Respir Crit Care Med 2012;185:645652 .

26 Bilton D, Bellon G, Charlton B, et al: Pooled analysis of two large randomised phase 3 inhaled mannitol studies in cystic fibrosis. J Cyst Fibros 2013;12:367-376.

27 Sawicki GS, Sellers DE, Robinson WM: High treatment burden in adults with cystic fibrosis: challenges to disease self-management. J Cyst Fibros 2009;8:91-96.

28 George PM, Banya W, Pareek N, et al: Improved survival at low lung function in cystic fibrosis: cohort study from 1990 to 2007 . BMJ 2011;342:d1008. 
29 Hodson ME, Penketh AR, Batten JC: Aerosol carbenicillin and gentamicin treatment of Pseudomonas aeruginosa infection in patients with cystic fibrosis. Lancet 1981;2: 1137-1139.

30 Jensen T, Pedersen SS, Garne S, Heilmann C, Høiby N, Koch C: Colistin inhalation therapy in cystic fibrosis patients with chronic Pseudomonas aeruginosa infection. J Antimicrob Chemother 1987;19:831-838.

31 Ramsey BW, Pepe MS, Quan JM, Otto KL, Montgomery AB, Williams-Warren J, Vasiljev-K M, Borowitz D, Bowman CM, Marshall BC, Marshall S, Smith AL: Intermittent administration of inhaled tobramycin in patients with cystic fibrosis. N Engl J Med 1999;340:23-30.

-32 McCoy KS, Quittner AL, Oermann CM, Gibson RL, Retsch-Bogart GZ, Montgomery AB: Inhaled aztreonam lysine for chronic airway Pseudomonas aeruginosa in cystic fibrosis. Am J Respir Crit Care Med 2008;178:921928
33 Assael BM, Pressler T, Bilton D, Fayon M, Fischer R, Chiron R, LaRosa M, Knoop C, McElvaney N, Lewis SA, Bresnik M, Montgomery $\mathrm{AB}$, Oermann $\mathrm{CM}$, AZLI Active Comparator Study Group: Inhaled aztreonam lysine vs. inhaled tobramycin in cystic fibrosis: a comparative efficacy trial. J Cyst Fibros 2013;12:130-140.

34 Lo D, VanDevanter DR, Flume P, Smyth A: Aerosolized antibiotic therapy for chronic cystic fibrosis airway infections: continuous or intermittent? Respir Med 2011;105(suppl 2):S9-S17.

35 Bakker EM, Volpi S, Salonini E, et al: Improved treatment response to dornase alfa in cystic fibrosis patients using controlled inhalation. Eur Respir J 2011;38:1328-1335.

36 Daniels T, Goodacre L, Sutton C, Pollard K, Conway S, Peckham D: Accurate assessment of adherence: self-report and clinician report vs. electronic monitoring of nebulizers. Chest 2011;140:425-432.

37 Geller DE, Weers J, Heuerding S: Development of an inhaled dry-powder formulation of tobramycin using PulmoSphere ${ }^{\mathrm{TM}}$ technology. J Aerosol Med Pulm Drug Deliv 2011;24: 175-182.
38 Konstan MW, Flume PA, Kappler M, Chiron R, Higgins M, Brockhaus F, Zhang J, Angyalosi G, He E, Geller DE: Safety, efficacy and convenience of tobramycin inhalation powder in cystic fibrosis patients: the EAGER trial. J Cyst Fibros 2011;10:54-61.

39 Geller DE, Nasr SZ, Piggott S, He E, Angyalosi G, Higgins M: Tobramycin inhalation powder in cystic fibrosis patients: response by age group. Respir Care 2014;59:388-398.

40 Schuster A, Haliburn C, Döring G, Goldman MH, Freedom Study Group: Safety, efficacy and convenience of colistimethate sodium dry powder for inhalation (Colobreathe DPI) in patients with cystic fibrosis: a randomised study. Thorax 2013;68:344-350.

41 Cystic Fibrosis Trust: UK cystic fibrosis registry annual data report 2013. http://www.cysticfibrosis.org.uk/media/598466/annual-data-report-2013-jul14.pdf. 